\title{
Institutional delivery and its associated factors: A community based cross-sectional study in Kavre district
}

\section{Shrestha S', Shrestha GK ${ }^{2}$}

'Sushila Shrestha, Lecturer; ${ }^{2}$ Geeta Kamal Shrestha, Associate Professor; Kathmandu University School of Medical Sciences, Dhulikhel, Kavre, Nepal

\begin{abstract}
Background: Health facility delivery is considered a critical strategy to improve maternal health. The Government of Nepal is promoting institutional delivery through different incentive programs and the establishment of birthing centers. The objective of this study was to identify utilization of institutional delivery and its associated factors.

Method: A descriptive cross-sectional study was carried out among the mothers of under five children in Dhungkharka. Pre-tested questionnaire was administered to 170 mothers between 15-45 years of age group. Household survey was done by using purposive sampling technique and face to face interview technique was used to collect the data from $1^{\text {st }}$ Julyto $30^{\text {th }}$ December 2014. Data was analyzed using simple descriptive statistic with SPSS version 16 . Association with institutional delivery was assessed by using chi-square test.

Results: Among the total participants, $90.0 \%$ of them had institutional delivery. The higher proportions of institutional delivery were found in both literate mothers $(p=0.001)$, and literate husband $(p=0.023)$. The proportion of institutional delivery among the mothers decided by their relatives (husband, father/mother-in-laws and other family members) for institutional delivery had higher portion $(p=0.048)$ of institutional delivery than participants who decide themselves. Conclusion: Utilization of institutional delivery was much higher than national figure. Institutional delivery was associated with both educational status of mothers and their husband. Decision made by husband, mother in-law, father in-law and other family members were also associated with institutional delivery. So, to increase institutional delivery, family members need to be encouraged for safe motherhood program.
\end{abstract}

Key words: Antenatal care, Door to door survey, Institutional delivery

\section{INTRODUCTION}

G lobally, nearly all (99\%) maternal deaths occur in low-income countries, mainly caused by nonutilization of available delivery services or delays in accessing such services ${ }^{1,2}$. Indeed, about half of all births in South Asia still occur at home ${ }^{3}$. A number of interventions have been implemented to increase the rate of facility delivery and access to emergency obstetric care, including the establishment of birth centers and maternity waiting homes, reduction of user fees, provision of incentives and birth preparedness packages ${ }^{4,5}$.

Improving maternal health is one of the United Nation's Millennium Development Goals (MDG 5) with a target

Address for correspondence

Sushila Shrestha

Lecturer, Kathmandu University School of Medical Sciences,

Dhulikhel, Kavre, Nepal

E-mail: sushshresth@yahoo.com of reducing the maternal mortality ratio (MMR) by three quarters by 2015 from its 1990 level $^{6}$. Globally, 289,000 maternal deaths occurred in 20137. Continuous care during pregnancy, delivery and the postpartum period is essential for maternal and newborn health. The most risky period for mother and child is during child birth and the first few days postpartum ${ }^{8}$.

An important strategy for decreasing maternal mortality is to utilize adequate, quality maternal health services in a timely manner. Delivery complications and death can be averted by a hospital or institution- assisted delivery with the assistance of skilled care providers within an enabling environment, and by effective referral systems $s^{5,9-11}$.

The government of Nepal has been implementing a free delivery policy since 2009, providing incentives to women who choose to deliver in a designated health facility ${ }^{9}$. However, the country continues to have a high MMR (229 per 100000 live births) ${ }^{12}$ with under 
utilization of maternal health services one of the reasons contributing to this high maternal death rate in Nepal.

The literature showed that several socio-demographic, economic and cultural factors play a role in determining whether women in Nepal use skilled birth attendants and institutional delivery.

Therefore, this study was conducted to identify the utilization of institutional delivery and its associated factors in rural community of Kavre District of Nepal.

\section{METHODOLOGY}

The Institutional Review Committee of Kathmandu University School of Medical Sciences, Dhulikhel Hospital approved the study protocol. All participants were informed about the nature and purpose of the study and verbal consent was obtained before the data collection.

A cross-sectional, descriptive, household survey was conducted in the Dhungkharka ward no. 6 and 7 from $1^{\text {st }}$ July to $30^{\text {th }}$ December 2014. Data collection was performed by face-to-face interview technique using structured questionnaires among 170 mothers of under-five children. The questionnaire comprises of two parts: the first part consisted of the socio-demographic information and second part included information related to utilization of institutional delivery and its associated factors. The mothers were selected using purposive sampling.

The study variable: Institutional delivery was defined as the mother who delivered their last baby in any institution (hospital, health center, birthing center) with trained health manpower.

The quality assurance of the data was maintained through daily assessment by questionnaires filled-in by the researcher herself; in cases of error or incompleteness immediate correction was done on the same day of the data collection. The data were entered into the Statistical Package for Social Science Software (SPSS) version 16.0 for analysis using the simple descriptive statistics. Associations with institutional delivery were explored by using chi-square test and $<0.05$ considered as statistically significant.

\section{RESULTS}

Mean age of participants was $24.9 \pm 4.7$ years with range of $17-45$ years. Among the total participants $17.1 \%$ of them were in age group of $\geq 30$ years. Majority (85.9\%) were literate, more than half (55.3\%) were employed and $79.4 \%$ of them had $\leq 2$ children. (Table 1 )
Table 1: Socio-demographic information of study participants $(n=170)$

\begin{tabular}{lcc} 
Variables & f & $\%$ \\
$\begin{array}{l}\text { Age(Years) } \\
<20\end{array}$ & 10 & 5.9 \\
$20-29$ & 131 & 70 \\
$\geq 30$ & 29 & 17.1 \\
Educational status & & \\
Literate & 146 & 85.9 \\
Illiterate & 24 & 14.1 \\
Husband's educational status & \\
Literate & 163 & 95.9 \\
Illiterate & 7 & 4.1 \\
Husband's occupation & & \\
Employed & 94 & 55.3 \\
Unemployed & 76 & 44.7 \\
Number of children & & \\
$\leq 2$ & 135 & 79.4 \\
$>2$ & 35 & 20.6 \\
\hline
\end{tabular}

Table 2: Obstetric and maternal characteristics of participants

\begin{tabular}{|c|c|c|}
\hline Variables & f & $\%$ \\
\hline \multicolumn{3}{|c|}{ ANC check-ups $(n=170)$} \\
\hline Yes & 164 & 96.5 \\
\hline No & 6 & 3.5 \\
\hline \multicolumn{3}{|c|}{ Number of ANC visit $(n=164)$} \\
\hline$<4$ visits & 33 & 20.1 \\
\hline$\geq 4$ visits & 131 & 79.9 \\
\hline \multicolumn{3}{|c|}{ Distance to birthing facility $(n=170)$} \\
\hline$\leq 1$ hour & 54 & 31.8 \\
\hline$>1$ hour & 116 & 68.2 \\
\hline \multicolumn{3}{|c|}{ Decision making for delivery $(n=170)$} \\
\hline Self & 34 & 20 \\
\hline Other than self & 136 & 80 \\
\hline
\end{tabular}

Among the total participants, almost all (164 [96.5\%]) of them had visited ANC, among 164 participants only $20 \%$ of them had visited ANC less than four times, $68.2 \%$ of them had more than one hour of distance to birthing facility. Only 34 (20\%) of the participants were able to decide themselves for delivery. (Table 2)

Among 170 participants, majority (90\%) of them had institutional delivery. Among mother delivered at institution, 84 (54.9\%) of them went health institution by walking, only $2 \%$ of them were unsatisfied with attitude of staff during delivery. Likewise $34.1 \%$ of them had labor pain at night, only $7.6 \%$ of them had more than 18 hours of labor pain. (Table3) 
Table 3: Utilization of institutional delivery

\begin{tabular}{|c|c|c|}
\hline Variables & f & $\%$ \\
\hline \multicolumn{3}{|l|}{ Place of delivery $(n=170)$} \\
\hline Institutional delivery & 153 & 90 \\
\hline Home delivery & 17 & 10 \\
\hline \multicolumn{3}{|c|}{ Means of transportation to reach health center $(n=153)$} \\
\hline Ambulance, taxi and local bus & 53 & 34.6 \\
\hline Walking & 84 & 54.9 \\
\hline Stretcher & 16 & 10.5 \\
\hline \multicolumn{3}{|c|}{ Satisfaction with attitude staff during delivery $(n=153)$} \\
\hline No & 3 & 2 \\
\hline Yes & 150 & 98 \\
\hline \multicolumn{3}{|c|}{ Labor pain starting time $(n=170)$} \\
\hline Morning & 49 & 28.8 \\
\hline Day & 21 & 12.4 \\
\hline Evening & 42 & 24.7 \\
\hline Night & 58 & 34.1 \\
\hline \multicolumn{3}{|l|}{ Duration of labor pain $(n=170)$} \\
\hline Up to 18 hours & 157 & 92.4 \\
\hline More than 18 hour & 13 & 7.6 \\
\hline
\end{tabular}

Table 4: Association between institutional delivery and selected demographic variables(170)

\begin{tabular}{|c|c|c|c|}
\hline Variables & \multicolumn{2}{|c|}{$\begin{array}{c}\text { Institutional } \\
\text { delivery }\end{array}$} & \multirow[t]{2}{*}{$\begin{array}{c}\mathbf{p} \\
\text { value }\end{array}$} \\
\hline Age in years & $f$ & $\%$ & \\
\hline$\leq 30$ years & 139 & 91.4 & \multirow{2}{*}{0.87} \\
\hline$>30$ years & 14 & 77.8 & \\
\hline \multicolumn{4}{|c|}{ Educational status } \\
\hline Literate & 137 & 93.8 & \multirow{3}{*}{0.001} \\
\hline Illiterate & 16 & 66.7 & \\
\hline \multicolumn{3}{|c|}{ Other than housewife } & \\
\hline \multicolumn{4}{|c|}{ Husband's educational status } \\
\hline Literate & 149 & 91.4 & \multirow{2}{*}{0.023} \\
\hline Illiterate & 4 & 57.1 & \\
\hline \multicolumn{4}{|c|}{ Husband's occupation } \\
\hline Employed & 86 & 91.5 & \multirow{2}{*}{0.472} \\
\hline Unemployed & 67 & 88.2 & \\
\hline \multicolumn{4}{|c|}{ Number of children } \\
\hline$\leq 2$ & 125 & 92.6 & \multirow{2}{*}{0.051} \\
\hline$>2$ & 28 & 80.0 & \\
\hline
\end{tabular}

The higher proportions of institutional delivery were found in both literate mothers $(p=0.001)$, and literate husband $(p=0.023)$.But we were not able to find significant association between institutional delivery and age of mothers, husband's occupation and number of children. (Table 4)
Table 5: Association between institutional delivery and obstetric related history

\begin{tabular}{|c|c|c|c|}
\hline Variables & \multicolumn{2}{|c|}{$\begin{array}{c}\text { Institutional } \\
\text { delivery }\end{array}$} & p value \\
\hline ANC visit & f & $\%$ & \\
\hline$<4$ visits & 30 & 90.9 & 1.00 \\
\hline$\geq 4$ visits & 120 & 91.6 & \\
\hline \multicolumn{4}{|c|}{ Distance to nearest health facility } \\
\hline$<1$ hour & 51 & 94.4 & \multirow{2}{*}{0.18} \\
\hline$\geq 1$ hour & 102 & 87.9 & \\
\hline \multicolumn{4}{|l|}{ Decision making } \\
\hline Self & 27 & 79.4 & \multirow{2}{*}{0.048} \\
\hline Other than self & 126 & 92.6 & \\
\hline
\end{tabular}

The proportion of institutional delivery among the mother who did not decide themselves had higher portion $(p=0.048)$ of institutional delivery than participants who decide themselves. This study was not able to find out the association between numbers of ANC visits and distance to nearest health facility for delivery. (Table 5)

\section{DISCUSSION}

This is a cross-sectional community-based survey to assess the institutional delivery and its associated factors. We found that $90 \%$ of mothers had institutional delivery. Institutional delivery was found to be associated with status of mothers and their husbands and decision making other than self for whether home or institutional delivery.

The study showed that $90 \%$ of participants had institutional delivery which is much higher the finding of the study conducted by Shah R where 55\% had delivered at a health facility ${ }^{13}$. Similar findings were shown in the study conducted by Dahal RK where $68.7 \%$ had delivered at a health facility ${ }^{10}$. Greater availability of private health services, easy transportation to Banepa and awareness of the community people towards the incentives given by government as per safe motherhood program could be the causes for the rise in health facility delivery in the study setting.

This study showed that $54.9 \%(n=153)$ of participants reached health center by walking, in contradiction to the study conducted by Sack E et. al. in which $8.2 \%$ and $30.4 \%$ of participants walked or used stretcher to reach the birthing center in Uganda and Zambia respectively ${ }^{14}$. This could be due to the difference in geographical structure and distance of the health facilities where women in Uganda and Zambia spent 62-68 minutes traveling to a clinic for delivery by cars, trucks, taxis etc. 
This study showed that only $3.5 \%$ of the participants had not gone for the ANC check-ups which is similar to the study conducted by Dahal RK where $3.2 \%$ mothers did not go for the ANC check-ups ${ }^{10}$. Another study conducted by Demilew YM showed that $33.1 \%$ of the women did not go to the ANC visits ${ }^{15}$. The difference might be due to the study area, physical distance and availability of transportation. Another reason could be due to the safe motherhood program of Nepal where women get Rupees 400 for 4 antenatal visits.

This study showed that $79.9 \%$ of the participants had visited ANC four or more than four times similar to the study conducted by Dahal RK where $79.4 \%$ of the women visited ANC more than four times ${ }^{10}$. Another study conducted by Shahabuddin ASM where $61 \%$ of the women had four or more ANC visits ${ }^{16}$.

This study showed that $68.2 \%$ of the participants had more than one hour of distance to birthing facility, whereas in a study conducted by Shah R only $24 \%$ of women had one hour or more distance to birthing facility ${ }^{13}$. Another study conducted by Teferra A.S. showed that $19.4 \%$ had one to two hours of time taken to visit the nearby health center ${ }^{17}$.

This study showed that only $20 \%$ of participants had self-decision making in the family which is slightly lower than the study conducted by Shah R where 29\% of women take final decision in the family alone ${ }^{13}$. The reason maybe, lack of women's autonomy in decision making for place of delivery, most of the times their husband, mother in-laws, father in-law and other family members take decisions in the family.

This study showed there is no association between institutional delivery and age of the participant contrast to the study conducted by Tadele $\mathrm{N}$ where statistically significant associations was found between age with the institutional delivery ${ }^{18}$.

This study showed the association between institutional delivery and educational status of the participant. In similar study conducted by Shahabuddhin ASM, significant association was seen between institutional delivery and educational level of the women ${ }^{16}$.

In this study participant occupation, husband education, and decision making had statistically significant association with institutional delivery which is similar with the study conducted by Paudel $G$ where age of marriage, age of first pregnancy, wait long for receiving services were found to have significant association with the institutional delivery ${ }^{19}$.

The strength of this study is that the data were collected by household survey with face to face interview. The main limitation of this study is that there might have been some degree of the over reporting and under reporting of information since it was collected based on recall of the mother.

\section{ACKNOWLEDGEMENT}

I take this opportunity to extend my sincere thanks and indebtedness to all those persons and dignitaries who helped me to complete this study.

My deep appreciation goes to Mr. Kedar Manandhar Lecturer of Kathmandu University School of Medical Science for his statistical guidance. I also would like to express my gratitude towards all those respondents who were included in this study for their kind co-operation and willingness to help me in the research work.

\section{REFERENCES}

1. Trends in Maternal Mortality: 1990 to 2010 [Internet]. Geneva: World Health Organization; 2012.[Cited 2017 Jan 14]. Available from:http://www.unfpa. org/webdav/site/global/shared/documents/ publications/2012/Trends_in_maternal_mortality_ A4-1.pdf]

2. Ronsmans C, Graham WJ. Maternal mortality: who, when, where, and why. Lancet. 2006;368(9542):1189200.

3. The Millenium Development Goals Report 2013 [Internet]. New York: United Nations; 2013. [Cited 2017 March14 ]. Available from:https://www.google.
com.np/?gws_rd=cr,ssl\&ei=Npl0We2jJsWe0gSu0p $\mathrm{jlBg} \# \mathrm{q}=$ Nations + U. + The + Millenium+Developmen $\mathrm{t}+$ Goals+Report+2013.+New+York:+United+Natio $n s ;+2013$.$] .$

4. Metcalfe R, Adegoke AA. Strategies to increase facility-based skilled birth attendance in South Asia: a literature review. International Health. 2013;5(2):96105.

5. De Brouwere V, Richard F, Witter S. Access to maternal and perinatal health services: Lessons from successful and less successful examples of improving access to safe delivery and care of the newborn. Trop Med Int Heal. 2010;15(8):901-9. 
6. Nepal Millennium Development Goals: Progress Report 2013. Government of Nepal, United Nations Country Team of Nepal; 2013. 1-106p.

7. Bank TW. Trends in Maternal Mortality: 1990 to 2013. Estimates by WHO, UNICEF, The World Bank and the United Nations Population Division [Internet]. Geneva: World Health Organization; 2014. [Cited 2017 March 16].Available from: www.who. int/ tivehealth/publications/monitoring/maternalmortality-2013/en/

8. Kerber KJ, de Graft-Johnson JE, Bhutta ZA, Okong P, Starrs A, Lawn JE. Continuum of care for maternal, newborn, and child health: from slogan to service delivery. Lancet. 2007;370(9595):1358-69.

9. Karkee R, Binns CW, Lee AH. Determinants of facility delivery after implementation of safer mother programme in Nepal: a prospective cohort study. BMC Pregnancy Childbirth . 2013;13(1):193.

10. Dahal RK. Factors Influencing the Choice of Place of Delivery among Women in Eastern Rural Nepal. Int J Matern Child Heal. 2013;1(2):30-7.

11. Assarag B, Dujardin B, Delamou A, Meski FZ, De Brouwere $V$. Determinants of maternal near-miss in morocco: too late, too far, too sloppy? PLoS One. 2015;10(1):e0116675.

12. Trends in maternal mortality:1990 to 2015 . World Health Organization, UNICEF WBG;2015.

13. Shah R, Rehfuess EA, Maskey MK, Fischer R, Bhandari $\mathrm{PB}$, Delius M. Factors affecting institutional delivery in rural Chitwan district of Nepal: a community-based cross-sectional study. BMC Pregnancy Childbirth. 2015;15:27.

14. Sacks E, Vail D, Austin-Evelyn K, Greeson D, Atuyambe LM, Macwan'gi M, et al. Factors influencing modes of transport and travel time for obstetric care: a mixed methods study in Zambia and Uganda. Health Policy Plan. 2016;31(3):293-301.

15. Demilew YM, Gebregergs GB, Negusie AA. Factors associated with institutional delivery in Dangila district, North West Ethiopia: a cross-sectional study. Afr Health Sci. 2016;16(1):10-7.

16. Shahabuddin A, De Brouwere V, Adhikari R, Delamou A, Bardaj A, Delvaux T. Determinants of institutional delivery among young married women in Nepal: Evidence from the Nepal Demographic and Health Survey, 2011. BMJ Open . 2017;7(4):e012446.

17. Teferra A, Alemu F, Woldeyohannes S. Institutional delivery service utilization and associated factors among mothers who gave birth in the last 12 months in Sekela District, North West of Ethiopia: A community - based cross sectional study. BMC Pregnancy Childbirth . 2012;12(1):74.

18. Tadele N, Lamaro T. Utilization of institutional delivery service and associated factors in Bench Maji zone, Southwest Ethiopia: community based, cross sectional study. BMC Health Serv Res. 2017;17(1):101.

19. Paudel G, Yadav UN, Thakuri SJ, Singh JP, Marahatta SB. Utilization of services for institutional deliveries in Gorkha District.Journal of Nepal Health Research Council. 2016;14(34):202-6. 